OPEN ACCESS

Edited by:

Maria de la Paz Fernandez,

Columbia University, United States

Reviewed by:

Joanne Yew,

University of Hawai'i at Mānoa,

United States

Jean-Christophe Billeter,

University of Groningen, Netherlands

Yehuda Ben-Shahar,

Washington University in St. Louis,

United States

${ }^{*}$ Correspondence:

Daisuke Yamamoto daichan@nict.go.jp

Specialty section:

This article was submitted to Individual and Social Behaviors,

a section of the journal

Frontiers in Behavioral Neuroscience

Received: 21 August 2020 Accepted: 11 November 2020

Published: 04 December 2020

Citation:

Sato K and Yamamoto D (2020) Contact-Chemosensory Evolution Underlying Reproductive Isolation

in Drosophila Species.

Front. Behav. Neurosci. 14:597428

doi: 10.3389/fnbeh.2020.597428

\section{Contact-Chemosensory Evolution Underlying Reproductive Isolation in Drosophila Species}

\author{
Kosei Sato and Daisuke Yamamoto*
}

Neuro-Network Evolution Project, Advanced ICT Research Institute, National Institute of Information and Communications Technology, Kobe, Japan

The main theme of the review is how changes in pheromone biochemistry and the sensory circuits underlying pheromone detection contribute to mate choice and reproductive isolation. The review focuses primarily on gustatory and non-volatile signals in Drosophila. Premating isolation is prevalent among closely related species. In Drosophila, preference for conspecifics against other species in mate choice underlies premating isolation, and such preference relies on contact chemosensory communications between a female and male along with other biological factors. For example, although $D$. simulans and $D$. melanogaster are sibling species that yield hybrids, their premating isolation is maintained primarily by the contrasting effects of 7,11-heptacosadiene (7,11-HD), a predominant female pheromone in D. melanogaster, on males of the two species: it attracts $D$. melanogaster males and repels $D$. simulans males. The contrasting preference for $7,11-\mathrm{HD}$ in males of these two species is mainly ascribed to opposite effects of 7,11-HD on neural activities in the courtship decisionmaking neurons in the male brain: $7,11-\mathrm{HD}$ provokes both excitatory and inhibitory inputs in these neurons and differences in the balance between the two counteracting inputs result in the contrasting preference for $7,11-\mathrm{HD}$, i.e., attraction in D. melanogaster and repulsion in $D$. simulans. Introduction of two double bonds is a key step in $7,11-\mathrm{HD}$ biosynthesis and is mediated by the desaturase desatF, which is active in D. melanogaster females but transcriptionally inactivated in $D$. simulans females. Thus, 7,11-HD biosynthesis diversified in females and 7,11-HD perception diversified in males, yet it remains elusive how concordance of the changes in the two sexes was attained in evolution.

Keywords: premating isolation, pheromones, hybrids, hydrocarbon metabolism, gustatory receptors, central integration, fruitless, doublesex

\section{INTRODUCTION}

The lack of gene flow or reproductive isolation is a prerequisite for the persistence of any species inhabiting the same place (Coyne and Orr, 2004). Premating as well as postmating isolation play roles in interfering with free gene flow, although neither would work as a perfect barrier against "interspecific hybridization" between populations that recently diverged. There exist cases where two populations of animals can produce fertile offspring and thus are judged to belong to the same 
species, yet mating between two individuals each from an alternative population barely happens in nature, implying that premating isolation could precede the development of postmating isolation (Shumer et al., 2017). The African and cosmopolitan populations of Drosophila melanogaster undergo such an incipient speciation that was driven by premating isolation ( $\mathrm{Wu}$ et al., 1995). Conversely, postmating isolation may occur prior to the development of premating isolation (Sweigart, 2010): the interspecific crosses happen at a high rate between $D$. virilis and $D$. americana, yet fertilization of eggs after mating hardly occurs in such crosses. In contrast to postmating isolation, premating isolation inevitably requires some cognitive process for discriminating a conspecific candidate partner from individuals of closely related species. If premating isolation takes place under the conditions where interspecies hybrids do not suffer from discernible fertility decrement (as expected to be the case for incipient speciation), assortative mating would likely be favored by sexual selection even when the adaptive (or fitness) advantage is limited. Here questions arise as to how the "perceptual shift" to favor a particular sexual trait in a potential mate develops and what genetic and neural mechanisms underlie this shift. Drosophila flies offer an ideal platform for addressing these evolutionary questions because of the comprehensive resource for genetic and neurobiological analyses in the model species $D$. melanogaster and because of the rich collection of species in the Drosophila phylogeny exhibiting distinct anatomical and behavioral characteristics (Hales et al., 2015).

This review covers mechanistic aspects of mating behavior, because the mechanistic understanding is critical for deciphering how animal behavior diversified thorough evolution. Homologous circuits that underly homologous behaviors need to be compared across species at the level of single cells, in which genes involved in behavioral divergence exert their specific actions. We review the current understanding of contact chemosensory mechanisms by which flies recognize conspecifics and discuss how species-specificity in pheromone perception and mate preference diversified in evolution.

\section{PHEROMONE PRODUCTION}

Cuticular hydrocarbons play roles as major sex pheromones in Drosophila (Jallon, 1984; Yew and Chung, 2017). These compounds are poorly volatile at room temperature and thus likely to be detected by contact chemoreceptors or gustatory receptors (Kohl et al., 2015). In D. melanogaster, 7-tricosene (7-T) is more abundant in males than females and acts as an aphrodisiac for a female, whereas 7,11-heptacosadiene (7,11-HD) and 7,11non-acosadiene (7,11-ND) are nearly exclusively produced by females and acts as an aphrodisiac for a male (Ferveur, 1997; Bontonou and Wicker-Thomas, 2014; Figure 1A). 7-pentacosene (7-P) is present in both sexes at lower levels also stimulates males to court (Ferveur, 1997; Bontonou and Wicker-Thomas, 2014). Conversely, 5-tricosene (5-T), 7-T and the acetylated long-chain hydrocarbon CH503 (Yew et al., 2009) present in D. melanogaster inhibits males from courting. Other hydrocarbons may be predominant in Drosophila species phylogenetically distant from D. melanogaster (Thompkins et al., 1993; Alves et al., 2010); in D. virilis females for example, $11-\mathrm{P}$ and 9-T are abundant cuticular hydrocarbons (Fan et al., 2013). Aside from hydrocarbons, cis-vaccenyl acetate (cVA) produced by male ejaculatory bulb functions as a potent suppressor of male courtship (Butterworth, 1969; Antony et al., 1985; GuiraudieCapraz et al., 2007). There is evidence that 7-T and cVA exert the courtship inhibitory effect only when these two compounds coexist (Billeter et al., 2009; Laturney and Billeter, 2016). The major source of hydrocarbon compounds is oenocytes associated with the epidermis (Ferveur, 1997; Bontonou and WickerThomas, 2014), genetic ablation of which allows one to obtain flies that produce almost no hydrocarbon compounds in their cuticles (Billeter et al., 2009). Unexpectedly, such oenocyte-less flies were highly attractive as a mating partner for both females and males, implying the loss of inhibitory compounds that normally prevent indiscriminate courtship (Billeter et al., 2009). Subsequent studies identified palmitoleic acid and non-esterified versions of the fatty acid methyl esters (Dweck et al., 2015; Lin et al., 2016) as non-sex-specific attractants, potentially accounting for the sexual attractiveness found in oenocyte-less flies. The site of synthesis of these fatty acids has not been determined, but fat bodies are a likely production site (Wicker-Thomas et al., 2009; Bontonou and Wicker-Thomas, 2014; Yew and Chung, 2017). Additionally, in cactus-feeding members of the Sophophora subgenus (but not in the subgenus Drosophila), the ejaculatory bulb produce male-specific triacylglycerides (TAG) that bear combinations of branched and linear fatty acyl side chains, which act as repellents for males upon transfer to the female mate during copulation (Chin et al., 2014).

The oenocyte-less $D$. melanogaster also provided important insights into the molecular basis for species discrimination in mate choice by males: $D$. melanogaster females without oenocytes were found to provoke strong courtship even from males of other species in the melanogaster species subgroup (Billeter et al., 2009). Perfuming oenocyte-less D. melanogaster females with female-specific 7,11-HD resumed species specific courtship, i.e., attracting males of $D$. melanogaster while repelling males of other members of the melanogaster species subgroup (Billeter et al., 2009). In fact, unlike D. melanogaster females, other members of the subgroup including D. simulans (Figure 1A), barely produce 7,11-HD (Jallon and David, 1987). These results indicate that the contrasting preference for 7,11-HD works as an effective barrier between $D$. melanogaster and other members of the species subgroup that prevents males from engaging in interspecific courtship.

On the other hand, the opposite preference for monoenes, particularly 7-T, constitutes a mating barrier in the partial reproductive isolation between the two strains of $D$. melanogaster, i.e., African (Zimbabwe: Z) vs. cosmopolitan populations (Grillet et al., 2012). As the amount of 7-T relative to 5 - $\mathrm{T}$ increases in courting males, cosmopolitan females become more receptive to mating, while African- $Z$ females become less receptive (Grillet et al., 2012). These observations reinforce the view that changes in hydrocarbon compositions may be one of the key events that precede reproductive isolation between two populations under 

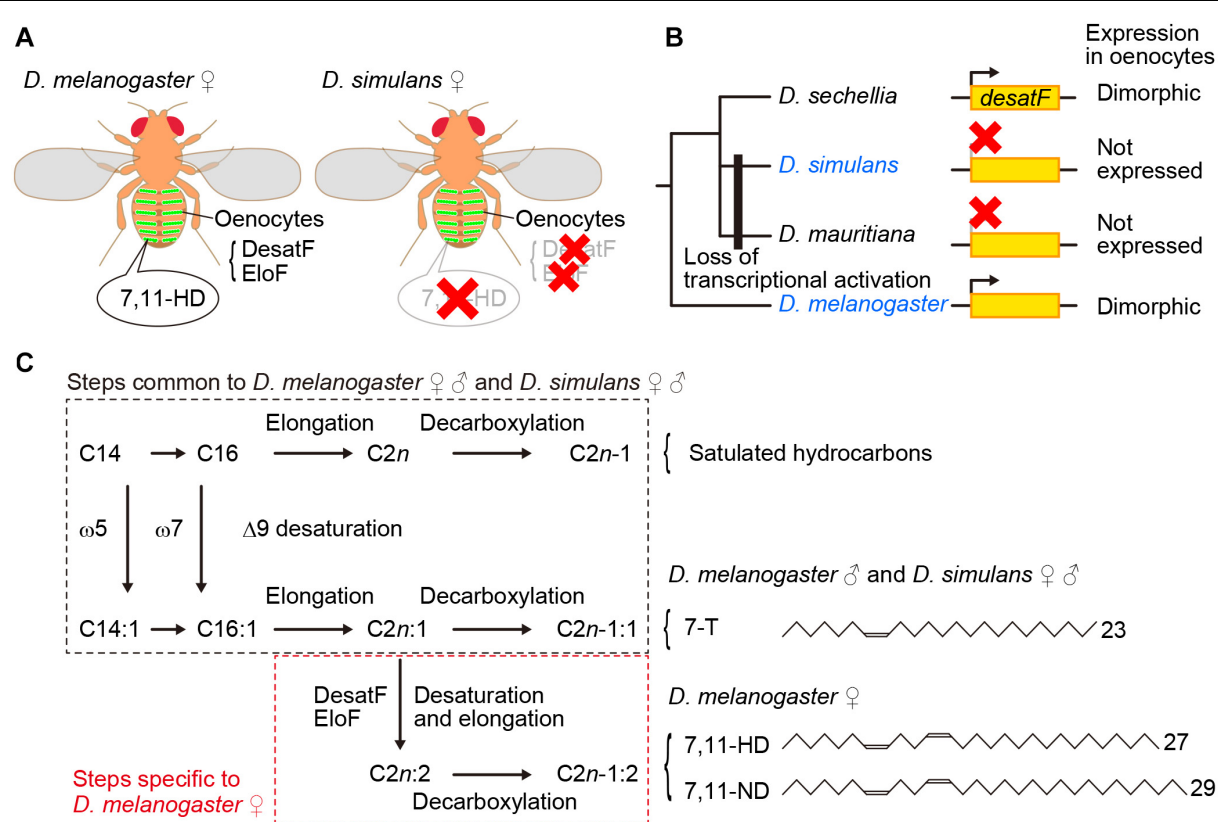

FIGURE 1 17,11-HD plays a key role for male mate choice in the D. melanogaster species subgroup. (A) 7,11-HD is a D. melanogaster female-specific pheromone synthesized in oenocytes as mediated by enzymes including DesatF and EloF. (B) DesatF expression is female-specific in $D$. melanogaster and $D$. sechellia, whereas it is transcriptionally inactivated in $D$. simulans and $D$. mauritiana. (C) Pathways for pheromone synthesis in $D$. melanogaster and $D$. simulans. 7-T is a monoene with a double bond at the 7 th carbon whereas $7,11-\mathrm{HD}$ is a diene with two double bonds each at the 7 th and 11 th carbon as the numbers in the compound names indicate.

incipient speciation, providing a rationale behind the search for evolutionary changes in hydrocarbon synthesis pathways.

Several genes encoding enzymes critical for introducing a double bond have been well-characterized in D. melanogaster, i.e., desaturase1 (desat1), desat2, desatF (also known as Fad2), Cyp4G1 (Qiu et al., 2012), and Bond (Ng et al., 2015). desat1 is a pleiotropic and indispensable gene transcriptionally regulated by 5 promoters each specifying unique spatiotemporal expression (Bousquet et al., 2012): among these, promoter-RE functions in oenocytes and is key for pheromone synthesis (Billeter et al., 2009), while promoter- $R C$ functions in neurons and is key for female receptivity (Bousquet et al., 2012; see below). desat 2 was discovered as a desat1 homolog in the genome of an African D. melanogaster strain, Tai (African-T), encoding desaturase with $\Delta 9$ specificity for omega-7 hydrocarbon precursors (in contrast to desat1 with $\Delta 7$ specificity for omega-5 hydrocarbon precursors; Dallerac et al., 2000). Remarkably, desat2 expression in African-T is female-specific, whereas desat2 is not expressed at all in the cosmopolitan Canton-special (CS) strain due to a promoter defect. Nucleotide sequence comparisons suggest that the desat2 gene structure in cosmopolitan populations is a descendant of that in the African counterpart (Takahashi et al., 2001). The presence or absence of functional desat 2 in the African and cosmopolitan D. melanogaster nicely explains why females of African D. melanogaster preferentially produce 5,9HD (an omega-7 hydrocarbon) rather than 7,11-HD (an omega5 hydrocarbon), the latter of which dominates in females of cosmopolitan D. melanogaster instead. In contrast, the different cuticular contents of $5-\mathrm{T}$ and $7-\mathrm{T}$ in males from the two populations have been demonstrated to be an important factor for females in choosing a mate, as discussed above. However, the different 5-T vs. 7-T ratio in African and cosmopolitan males cannot be ascribable to the presence or absence of functional desat 2 in the respective genomes, because males do not exhibit desat 2 expression in both populations. Thus, the significance of the discovered genomic changes in the desat 2 gene in incipient speciation in D. melanogaster populations has not been fully validated.

desat $F$ was identified as the gene that plays a central role in the synthesis of 7,11-HD and other dienes with two double bonds that are predominant in D. melanogaster females (Chertemps et al., 2006): DesatF catalyzes the reaction to introduce the second double bond into fatty acid precursors (Figures 1B,C). It was shown that female-specific desatF expression relies on a female-determinant, Transformer (Tra), and desatF knockdown in females results in a dramatic increase in monoenes (e.g., 7-T) at the expense of dienes (e.g., 7,11-HD). Comprehensive species comparisons of the desatF structure and expression unraveled the exceedingly complex evolutionary changes this gene underwent (Shirangi et al., 2009). Although a conserved desat $F$ sequence is recognizable in the genomes of 18 out of 24 species examined, it is not functional in 9 species: the desatF gene is translationally inactive in 6 species (although desatF in some species retains an intact open reading frame, ORF) and it harbors mutations in the coding sequence in 3 species (Shirangi et al., 2009). The desatF gene in some species underwent multiple transitions, e.g., once transcriptionally inactivated, it was transcriptionally reactivated and ultimately ORF-disrupted 
(Shirangi et al., 2009). Remarkably, female-specific expression as in D. melanogaster is not conserved across species that carry an active desatF gene: among the species examined, D. sechellia, D. errecta, and D. melanogaster are the only ones that exhibit desatF sexually dimorphic expression. The transitions between the monomorphic and dimorphic expression were found to be associated with the loss and gain of distinct biding sites for the sex-determinant transcription factor Doublesex (Dsx) in the cis-regulatory region of the desatF gene, respectively (Shirangi et al., 2009). In the D. melanogaster species subgroup, a common ancestor presumably had dimorphic expression of desatF and thus expressed 7,11-HD, which was subsequently lost as a result of transcriptional inactivation of desat $F$ in the clade containing D. simulans and D. mauritiana, while dimorphic expression was sustained in the clade to D. melanogaster (Figure 1B). It is thus plausible that reproductive isolation between the two sympatric sibling species D. melanogaster and D. simulans was endowed, in part, by cis element mutations in the desatF gene, which removed 7,11-HD from females of $D$. simulans, in concordance with changes in the preference for 7,11-HD in males (see below).

Yet another gene of interest is fatty acid elongase $F$ (eloF), which elongates the DesatF products omega-7,11 fatty acids, the precursors of 7,11-HD and 7,11-ND in D. melanogaster females (Chertemps et al., 2007; Figure 1C). eloF is expressed in a femalebiased manner in D. melanogaster (Chertemps et al., 2007) and D. sechellia (Combs et al., 2018) and is not expressed at all in D. simulans (Chertemps et al., 2007; Figure 1A). What we see here with eloF is exactly the above-described pattern of desatF expression in these three species. It remains an open question whether this kind of coordinated evolution of eloF and desatF can be generalized into other clades of the Drosophila phylogeny.

cVA is probably the most studied among pheromones in Drosophila, but little is known about its biosynthesis. Unlike major cuticular hydrocarbon pheromones that are produced by oenocytes, cVA is secreted into the lumens of ejaculatory bulb in a male and ejected, together with sperms, into the female genitalia during copulation, reducing the sexual attractiveness of that female for other males (Antony et al., 1985). In addition to such an anti-aphrodisiac effect, cVA enhances aggression among unfamiliar males (Wang and Anderson, 2010; Wang et al., 2011) but reduces aggression among familiar males (Liu et al., 2011), and promotes non-sex-specific aggregation in a context-dependent manner (Bartelt et al., 1985; Wertheim et al., 2002; Lebreton et al., 2014; Cazalé-Debat et al., 2019), and suppresses male courtship toward a virgin female after his exposure to a mated female (Ejima et al., 2007; Keleman et al., 2012). Radioactive tracer labeling of metabolites supported the hypothesis that the male ejaculatory bulb synthesizes cVA from acetate as a starting compound, yet the vaccenyl moiety is of an unknown origin (Guiraudie-Capraz et al., 2007). Notably, in D. buzzatii, radiolabeled acetate similarly incubated with male ejaculatory bulb yields two ketone compounds, i.e., (Z)-10-heptadecen-2-one, an aggregation pheromone, and its antagonist, 2-tridecenone (Skiba and Jackson, 1993). A large number of long-chain acetates, alcohols and ketones have been reported as aggregation pheromones in Drosophila, and the composition of pheromone blends varies widely across species
(Symonds and Wertheim, 2005; Lebreton et al., 2017). It remains to be determined whether these aggregation pheromones also play roles as sex pheromones, and if so, how significant they are in reproductive isolation in speciation events.

\section{SEX PHEROMONE RECEPTION}

In the previous section, we saw that a single pheromone may exert contrasting reactions in different species. A favored interpretation for this would be that a receptor for the pheromone responds differently in different species. In this section, we review our current understanding of contact chemoreceptors for pheromones in Drosophila and evaluate the above hypothesis.

Electrical recordings of receptor potentials and spiking activities from a receptor cell are the straightforward functional demonstration of ligand-receptor interactions. The female pheromone 7,11-HD was demonstrated to provoke discharges from chemosensory neurons in the foreleg tarsi of D. melanogaster males (Toda et al., 2012; Figure 2A). When a male fly taps the female abdomen with his foreleg during courtship, these chemosensory neurons will be stimulated by cuticular hydrocarbon compounds on the female abdomen. A fraction of the foreleg chemosensory neurons express the neural masculinizing protein Fruitless (FruM), and these $f r u[+]$ chemosensory neurons exhibit sex differences in the central projection pattern (Kimura et al., 2019; see below). A subset of such $\mathrm{fru}[+]$ chemosensory neurons in foreleg tarsi express $p p k 23$ and related genes that encode Degenerin/Epithelial $\mathrm{Na}^{+}$channel (Deg/ENaC) family proteins, which have been implicated in 7,11HD-dependent male courtship based on behavioral phenotypes upon targeted knockdown and $\mathrm{Ca}^{2+}$ neural activity imaging (Liu et al., 2012; Lu et al., 2012; Thistle et al., 2012; Vijayan et al., 2014; see below; Figure 2B).

The identity of 7,11-HD responsive cells was further defined by $\mathrm{Ca}^{2+}$ activity imaging: the relevant tarsal sensillum houses a pair of $\mathrm{fru}[+] / p p k 23[+] / p p k 29[+]$ cells, each having a complementary function such that one (the F-cell) responds to the female pheromone 7,11-HD but not the male pheromone 7 -tricosense (7-T), while the other (the $\mathrm{M}$-cell) responds to 7 T but not 7,11-HD (Thistle et al., 2012; Figure 2B). Up- and down-regulation of F-cells promote and repress male courtship activities, respectively, and the converse effects are observed when M-cells are similarly manipulated (Lu et al., 2012; Starostina et al., 2012; Thistle et al., 2012; Toda et al., 2012). The F-cells are molecularly distinguishable from the $\mathrm{M}$-cells by their expression of $p p k 25$, which is required specifically for the 7,11-HD responses of these cells (Vijayan et al., 2014; Figure 2B). The F-cells on foreleg tarsi are probably the major sensor for 7,11-HD, although there are other cells that are thought to be additional 7,11-HD sensors (see below). The F-cells and M-cells are present in both sexes, and their sex-specific functions are encoded by sex-specific functions via sexually dimorphic projections (Thistle et al., 2012).

7-T may stimulate additional cells other than the M-cells in the tarsus, including Gr32a-expressing bitter responsive cells (Koganezawa et al., 2010; Wang and Anderson, 2010) that are negative for both ppk23 (Thistle et al., 2012) and fru 


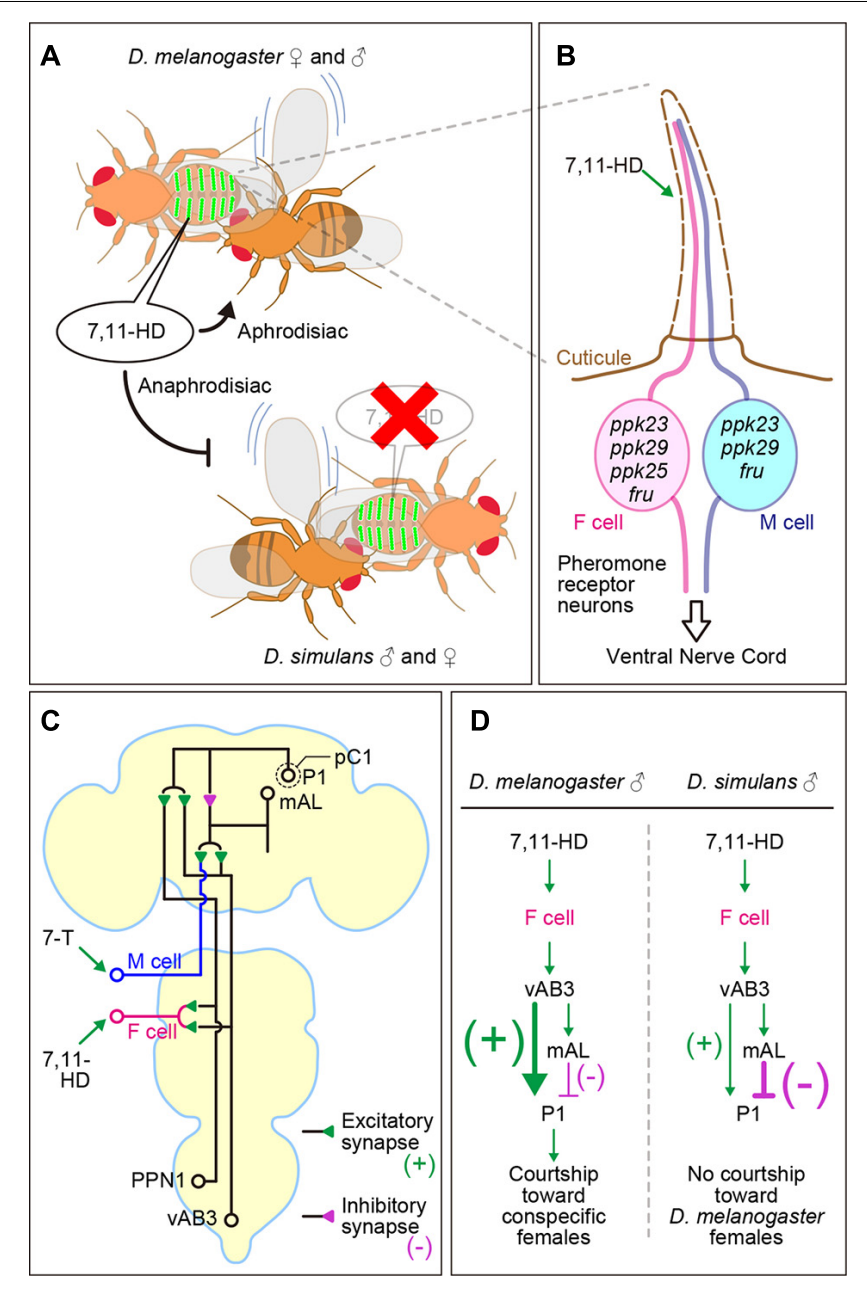

FIGURE $2 \mid D$. melanogaster males are attracted and $D$. simulans males are repelled by 7,11-HD. (A) Contrasting responses to 7,11-HD underlie conspecific mate choice. (B) F-cell and M-cell in the male tarsi sense female pheromones (e.g., 7,11-HD) and male pheromones (e.g., 7-T), respectively. The F-cell and M-cell both express ppk23, ppk29 and fru, while ppk25 expression is F-cell specific. (C) Central pathway for 7,11-HD perception in male flies involves ascending excitatory (+) neurons including vAB3 and PPN1, mAL inhibitory (-) interneurons, and courtship triggering P1 excitatory (+) interneurons. (D) mAL-mediated inhibition overwhelms vAB3-mediated excitation in P1 neurons in $D$. simulans males but not $D$. melanogaster males, resulting in opposite responses to 7,11-HD in males of these two species. P1 represents a male-specific subset in the $\mathrm{pC} 1$ neuron group (circled by a dotted line). Circles, lines, and triangles indicate somata, neurites, and presynaptic terminals of neurons, respectively.

(Koganezawa et al., 2010) expression; ppk23-positive cells are located predominantly in the ventral sensory hairs, whereas Gr32a-positive cells are located mostly in the dorsal sensory hairs (Ling et al., 2014). Furthermore, Lacaille et al. (2007) showed, using a tungsten electrode inserted into the base of a sensillum, that some bitter-sensitive cells on a labial palp (i.e., mouth) contained sensory neurons responsive to low concentrations of 7-T, a pheromone that inhibits male courtship. Because male flies lick female genitalia during courtship, sensory neurons on the labial palp are likely activated in courting males.

7-T is not the sole ligand for the M-cells: cVA also activates these cells (Thistle et al., 2012). This is rather surprising, because cVA is volatile and known to activate primarily the olfactory receptor neurons expressing Or67d (Ha and Smith, 2006; Kurtovic et al., 2007; Datta et al., 2008; Ruta et al., 2010; Liu et al., 2011) and secondarily those expressing Or65a
(Ejima et al., 2007; Liu et al., 2011; Lebreton et al., 2014) in the antenna. In addition to these tarsal sensory cells, a subset of gustatory cells respond to fly cuticle extracts and promote mating activities in both female and male D. melanogaster (Koh et al., 2014; He et al., 2019).

What are the roles of these contact chemosensory cells in sexual isolation among Drosophila species? Fan et al. (2013) showed that RNAi-mediated knockdown or genetic ablation of Gr32a-expressing neurons in D. melanogaster males restores the attractiveness of oenocyte-less $D$. melanogaster females that were perfumed with cuticular extracts from females of other Drosophila species (i.e., D. simulans, D. yakuba, or D. virilis) or with synthetic $7-\mathrm{T}, 9-\mathrm{T}$ and/or 11-P, the treatments that otherwise abrogate the sex appeal of $D$. melanogaster females (Fan et al., 2013). These results suggest that Gr32a-expressing sensory neurons that are responsive to a broad spectrum of 
hydrocarbons play a key role in the conspecific preference in $D$ melanogaster males. Subsequently, similar behavioral assays were conducted with Gr32a-knockout D. simulans, which was generated by CRISPR/Cas9-mediated targeted mutagenesis, yielding a contrasting result: Gr32a mutant males of $D$. simulans displayed no sign of impairment in discriminating conspecifics from other species, exhibiting a strict preference for females of the same species (Seeholzer et al., 2018; Ahmed et al., 2019). The lack of effect of Gr32a knockdown on mating discrimination is intriguing in view of the fact that not only Gr32a expression in tarsal sensory neurons but also the function of Gr32a in bitterness perception were conserved between $D$. melanogaster and D. simulans (Ahmed et al., 2019). ppk25 knockout in D. simulans, on the other hand, diminished male courtship activities toward conspecific females, as in D. melanogaster (Ahmed et al., 2019). However, the primary stimulant of ppk25expressing tarsal sensory neurons in D. melanogaster is 7,11-HD, which repels $D$. simulans males, implying that $p p k 25$-expressing tarsal neurons in $D$. simulans promote male courtship when activated by a pheromone other than 7,11-HD. Alternatively, the pathway initiated by the $p p k 25$-expressing sensory neurons is not a simple accelerator of male courtship activity; instead, inputs through this pathway may gain either positive or negative valence upon central integration, which varies depending on the species and context (Figures 2C,D). It is an interesting question as to which mechanisms - the peripheral or central mechanisms - are more frequently modified for sexual isolation in incipient speciation.

\section{MOLECULAR IDENTITY OF CONTACT-CHEMICAL PHEROMONE RECEPTORS}

It remains an open question as to which proteins function as specific receptors for pheromones. As described above, the reception of major contact-chemosensory pheromones is mediated by cells that express select $p p k$ family members (e.g., ppk23, ppk25, and ppk29) or Gr32a. Gr68a (Bray and Amrein, 2003) and Gr33a (Watanabe et al., 2011) have also been suggested to have roles in mating behavior. More recent works have further shown that a subset of the ionotropic glutamate receptor (IR) family contributes to courtship behavior (Koh et al., 2014; $\mathrm{He}$ et al., 2019). Are these proteins by themselves function as receptors for pheromones? Are they required for signal transduction downstream of receptors? Liu et al. (2020) argue that $p p k 23, p p k 25$, and $p p k 29$ form a functional receptor for 7,11-HD based on the observation that the otherwise 7,11-HDunresponsive M-cells acquire sensitivity to this compound when the $p p k$ trio is expressed in the cells. It should be noted that only $p p k 25$ needs to be overexpressed because $p p k 23$ and $p p k 29$ are endogenously expressed in the M-cells. This finding in the $\mathrm{M}$-cells is in line with the aforementioned result in the F-cells that ppk25 knockdown abrogates their sensitivity to 7,11-HD, which resumes upon $p p k 25$ overexpression (Vijayan et al., 2014). Nonetheless, these observations do not exclude the possibility that the $p p k$ proteins are not receptors that bind 7,11-HD but rather are their effector channels for electrogenesis, amplifying signaling downstream of the receptors ( $\mathrm{Ng}$ et al., 2019). ppk25 overexpression might have enhanced the outputs of the receptors that intrinsically respond to a wide spectrum of agonists so that even small responses that might otherwise be overlooked become detectable by the experimental manipulation.

Gr32a is another candidate receptor for hydrocarbon pheromones, particularly 7-T. Gr32a belongs to the insect chemoreceptor superfamily, which is composed of 68 Grs and 62 Ors, which are 7-pass transmembrane proteins that form ion channels on their own without any involvement of additional cytoplasmic factors (i.e., ionotropic receptors), unlike mammalian chemoreceptors, which are typically 7-pass membrane proteins with inverse topology (in comparison with that of insect receptors) that act via a G-protein mediated transduction cascade (i.e., metabotropic receptors; Sato et al., 2008, 2011). A recent cryogenic electron microscopy (cryoEM) study on an Or-namely, the odorant receptor co-receptor (Orco) -in an insect identified a crevice of $10-\AA$ depth and $20 \AA$ length within the extracellular leaflet, along which several residues known to affect ligand sensitivity lie, and which is thus likely to serve as a binding site for ligands (Butterwick et al., 2018). Following the analogy of Orco, Gr32a may have ligand binding activity. However, Gr32a is widely expressed in contact-chemosensory neurons that respond to a wide spectrum of ligands, particularly those known as bitter tastants, raising the question of how the Gr32a protein confers the ligand specificity on the sensory neurons. A recent exhaustive analysis of ligand-receptor-neuron relationships for gustatory responses in the labial palp defined Gr32a, Gr33a, Gr39a.a, Gr66a, Gr89a, and Gr93a as commonly expressed receptors (CERs) in bittersensitive receptors, which are equivalent to Orco in olfactory receptors (Dweck and Carlson, 2020; Figure 3). Typically, two, three, or four fixed members of CERs need to be coexpressed for normal bitter sensitivity: Gr32a, Gr33a, and Gr66a are the triple constituents and Gr33a, Gr39a, Gr66a, and Gr93a are the quadruple constituents essential for responding to caffeine and some other compounds in a subset of bittersensitive chemosensory neurons housed in I-a and I-b sensilla, respectively. When one component of the trio or quartet is lost, the neurons may simply become unresponsive to nearly all bitter tastants to which they normally respond or, alternatively, the neurons may acquire a novel ligand selectivity depending on their neuron type, which would suggest competition among multiple Gr species expressed in the same neuron in forming a functional heteromeric receptor for bitter tastants (Dweck and Carlson, 2020). Thus, the response spectrum of a neuron may change dependent on the combination of Gr species coexpressed and the relative abundance of different Grs. These considerations tempted us to suggest that Gr32a may contribute to the reception of 7-T and other pheromones as one of the CERs.

Then, the question remains as to how the response spectrum of a contact-chemosensory neuron is specified. The I-a and I-b sensilla are morphologically similar, but each respond to mutually exclusive sets of bitter compounds in $D$. melanogaster: for instance, caffeine elicits responses from I-b but not I-a, whereas berberine elicits responses from I-a but not I-b. However, 


\section{D. melanogaster}

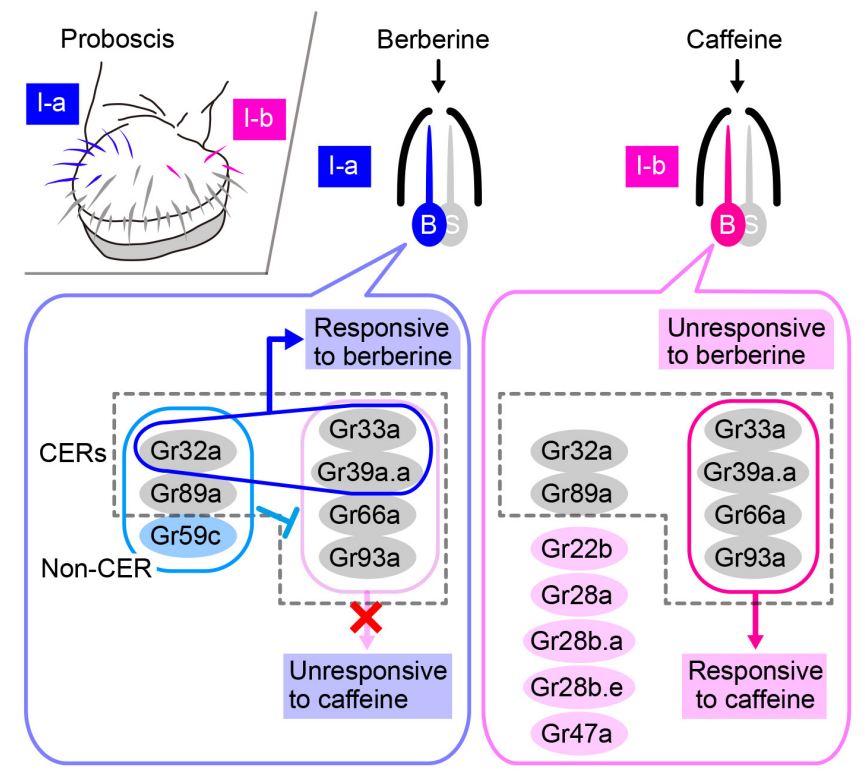

FIGURE 3 | Combination of several GRs expressed in a single neuron determines the response spectrum of the cell. Upper left-side panel: Spatial localization of bitter-responsive I-a (blue) and I-b (red) sensilla on the labellum. Right-side panels: The bitter-responsive neuron (labeled as "B") of each sensillum expresses a different combination of Gustatory receptors (Grs), five of which are referred to as "Commonly Expressed Receptors" (CERs; in dotted rectangles) and are expressed in every bitter-responsive neuron on the labellum. Expression of Gr32a, Gr33a, and Gr39a.a together confers a berberine sensitivity on the I-a sensillum, whereas expression of Gr33a, Gr39a.a, Gr66a, and Gr93a together confers a caffeine sensitivity on the I-b sensillum. However, the latter four Grs are unable to confer a caffeine sensitivity on the I-a sensillum, because Gr32a, Gr59b, and Gr89a are coexpressed in this sensillum.

the I-a sensillum acquires the entire response spectrum of I-b and thus becomes responsive to caffeine when the non-CER Gr59c is lost or when one CER, either Gr32a or Gr89a, is lost (Dweck and Carlson, 2020). Conversely, misexpression of Gr59c in the I-b sensillum confers the I-a type response spectrum on the I-b sensillum, provided that Gr32a and Gr89a are intact (Dweck and Carlson, 2020). This and other experiments demonstrate that the I-a sensillum does not respond to caffeine and other ligands that normally activate the I-b sensillum, because Gr59c in addition to the CER Gr32a and Gr89a coordinately suppress the responses to these substances (Dweck and Carlson, 2020). These observations imply that evolutionary loss or gain of the expression of just one of the Gr-coding genes could produce substantial changes in the ligand specificity of a subset of contact-chemosensory neurons, thereby leading to diversified pheromonal responses that potentially impact speciation events.

\section{CENTRAL PROCESSING OF CONTACT-CHEMICAL PHEROMONE INFORMATION IN EVOLUTION}

Contact chemosensory information plays a pivotal role in recognizing potential mating partners, making a decision to court, and initiating the mating motor program in Drosophila. One pheromone substance may induce different behavioral responses in recipients of different species, with the differences potentially arising from the different response properties of peripheral receptor cells as discussed above or the different processing of pheromone inputs in the central nervous system (CNS). In this section, we focus on central mechanisms underlying the different behavioral responses to contact chemosensory pheromones among Drosophila species in the context of mate preference. Unfortunately, there are no means for systematic labeling of a single neuron along the entity of the cell in non-model species, hampering circuit dissection in these species. Due to this technical difficulty, species differences in the structure and function of central neurons have been least explored. One exception is a study which successfully unraveled the central circuit basis for the biased preference of conspecific over sibling species females by $D$. simulans males (Seeholzer et al., 2018).

The central circuit for mating behavior has been extensively analyzed in D. melanogaster (Kohl et al., 2013; Yamamoto and Koganezawa, 2013), in which FruM-positive neurons tend to interconnect in forming the core portion of the circuit (Ruta et al., 2010; Yu et al., 2010). A male-specific interneuron group called P1 (Kimura et al., 2008) or its subpopulation (Ishii et al., 2020) plays a decisive role in initiating courtship behavior (Yamamoto and Koganezawa, 2013; Figure 2C). The P1 neuron cluster was first identified as a subset of FruM/Dsx double-positive neurons (20 neurons per hemisphere) that could drive test females to perform male-type courtship behavior toward a target female when those neurons were clonally masculinized in the test female brain by the $t r a^{1}$ mutation (Kimura et al., 2008); the $t r a^{1}$ mutation removes the DsxF feminizer protein that otherwise kills 
P1 precursor cells during development, thereby allowing malespecific P1 to persist throughout the adult stage in the female brain (Kimura et al., 2008; see also Ren et al., 2016). In a solitary male, artificial activation of $\mathrm{P} 1$ neurons via heat-sensitive $\mathrm{dTrpA} 1$ channels or the light-activatable channel Channelrhodopsin induces the early steps of courtship, i.e., unilateral wing extension and vibration for singing and tapping with forelegs (Kohatsu et al., 2011; Kohatsu and Yamamoto, 2015). $\mathrm{Ca}^{2+}$ imaging of P1 neurons in a tethered male on a treadmill revealed that these neurons are excited when the male touches the female abdomen with his foreleg (Kohatsu et al., 2011). P1 neurons remain continuously and dynamically active throughout the courtship achievements under freely moving (Grover et al., 2016, 2020) as well as tethered (Kohatsu and Yamamoto, 2015) conditions. Contact chemosensory sensation of female cues is crucial for courtship initiation by the male, based on the finding that touch-induced chasing is blocked when the virgin female as a courtship target is perfumed with the hexane extract of male cuticles (Kohatsu et al., 2011). P1 neurons have been shown to be excited when the male foreleg tarsus is touched by a glass rod, provided that it is coated with the hexane-extract of fly cuticles (Kohatsu et al., 2011). Notably, P1 neurons exhibit $\mathrm{Ca}^{2+}$ rises upon tarsal stimulation with the extracts of male as well as female cuticles, although female extracts provoke significantly larger responses than male extracts do (Kohatsu et al., 2011). These and other observations support the notion that P1 neurons in the male brain receive contact-chemosensory inputs originating from tarsal pheromone receptors upon the touch of a female and drive persistent courtship toward the female. P1 neuron outputs are relayed by descending interneurons that activate the motor pattern generator for courtship acts (Clyne and Miesenböck, 2008; Kohatsu et al., 2011; von Philipsborn et al., 2011; Kimura et al., 2015; Cande et al., 2018; Clemens et al., 2018; Namiki et al., 2018; McKellar et al., 2019). A subset of P1 neurons provoke not only courtship toward a female but also aggression toward a male (Inagaki et al., 2014; Hoopfer et al., 2015; Koganezawa et al., 2016), presumably dependent on the sensory inputs they receive (Ishii et al., 2020; Wohl et al., 2020), while inhibiting sleep in a manner dependent on the internal state of the fly (Chen et al., 2017; Wu et al., 2019). Note, however, that subpopulations of the $\mathrm{P} 1$ cluster and the $\mathrm{pC} 1$ cluster to which the P1 cluster belongs need further clarification in terms of functional specialization (see Costa et al., 2016). The internal states, such as the motivational state and sleep/arousal cycle, affect $\mathrm{P} 1$ activities via dopaminergic and GABAergic synaptic inputs to promote and inhibit courtship, respectively (Crickmore and Vosshall, 2013; Zhang et al., 2016, 2018).

Given that P1 neurons in the brain trigger the lower center that produce motor outputs for courtship actions, how does the pheromone information received by sensory cells in the legs and mouth reach to the P1 neurons? The pathways through which contact chemical pheromone inputs reach to P1 neurons were revealed in D. melanogaster by anatomical detection of putative synaptic contacts in conjunction with $\mathrm{Ca}^{2+}$ imaging to monitor the neural activities across synapses (Figure 2C). The majority of the ppk23-positive tarsal chemosensory neurons responsive to 7,11-HD appear to terminate their axons in the prothoracic ganglion (Mellert et al., 2010; Kimura et al., 2019), and thus direct contact with brain-intrinsic P1 neurons must, if any, be limited. Instead, the ascending interneuron group vAB3 intervene in the communication between the $p p k 23$-positive sensory neurons and P1 neurons: vAB3 neurons originate in the abdominal ganglion and terminally project to the lateral protocerebrum, the brain region $\mathrm{P} 1$ neurons densely innervate, with en passant arbors in the prothoracic and suboesophageal ganglia (Clowney et al., 2015). vAB3 neurons are excited when the male touches the female abdomen with his foreleg, and vAB3 activation by Ach iontophoretically applied to the prothoracic neuropil induces $\mathrm{Ca}^{2+}$ elevation in $\mathrm{P} 1$ neurons, which is blocked by vAB3 severing (Seeholzer et al., 2018). Thus, vAB3 provides an excitatory pathway that conveys the female pheromone information from leg sensory neurons to P1 neurons that initiate male courtship. Another group of neurons that are likely presynaptic to $\mathrm{P} 1$ are the $\mathrm{mAL}$ neurons, which are fru-positive GABAergic inhibitory interneurons (Koganezawa et al., 2016) that are sexually dimorphic in both structure and cell number (Kimura et al., 2005). A sexually dimorphic neurite of mAL likely contacts, in a male-specific manner, the axon terminals of Gr32a-expressing tarsal sensory neurons (Koganezawa et al., 2010). Remarkably, mAL neurons exhibit $\mathrm{Ca}^{2+}$ elevation in response to activation of vAB3, whose en passant arbors appear to intermingle with $\mathrm{mAL}$ arbors in the suboesophageal ganglion. This observation raises the possibility that vAB3 could also deliver an inhibitory input to P1 neurons via $\mathrm{mAL}$ neurons. Indeed, $\mathrm{P} 1$ activation in response to stimulation of vAB3 is significantly greater after $\mathrm{mAL}$ severing, supporting the notion that the reception of aphrodisiac female pheromones by the leg chemosensory receptors ultimately provokes not only excitatory responses but also inhibitory responses in $\mathrm{P} 1$ neurons, the decision-making neural center for male courtship behavior. Convergence of these two antagonistic inputs at nearly the same time might create a sensitized condition where additional cues easily bias the activity of P1 neurons that are involved in decisionmaking to court or not, allowing the male fly to judge whether the confronting target for courtship is truly an appropriate potential mate. There is yet another ascending interneuron group, PPN1, that convey inputs originating from $p p k 23 / p p k 25$ double-positive pheromone receptors (female-pheromone sensitive F-cells) to P1 neurons; PPN1 neurons act as excitatory presynaptic fibers for P1 and, at the same time, act as an element in the inhibitory pathway impinging on $\mathrm{P} 1$ via $\mathrm{mAL}$ interneurons (Kallman et al., 2015). In contrast to F-cell axons, which terminate mostly in the thoracic ganglia, a subset of ppk23positive and ppk25-negative M-cells extend their axons beyond the thorax and terminate in the suboesophageal ganglion, where these axons seem to come into contact with an $\mathrm{mAL}$ neurite (Kallman et al., 2015). As a consequence, the M-cell activator 7-T primarily inhibits P1 neuron activity and thus represses male courtship, whereas the F-cell activator 7,11-HD elevates P1 neuron activity despite its inhibitory effect through mAL and ultimately promotes male courtship (Kallman et al., 2015). Thus, we find that a common excitatory pheromone input is fed into two pathways, one converts the excitatory signal into an inhibitory signal, while the other conveys the excitatory signal 
without inverting its sign, and the two pathways ultimately converge onto the $\mathrm{P} 1$ neurons.

This principle would offer a simple means to fine-tune the sensitivity of a decision-making neural center to incoming sensory cues. In fact, different preferences for 7,11-HD in males of the D. melanogaster species subgroup are suggested to involve a shift in the excitatory vs. inhibitory balance in contact chemosensory inputs impinging on P1 neurons (Figure 2D). As discussed in the preceding sections, males of $D$. simulans avoid 7,11-HD, which is specifically enriched in female cuticles of $D$. melanogaster. The neural pathway through which 7,11$\mathrm{HD}$-induced activities travel to $\mathrm{P} 1$ neurons is, in principle, conserved between D. melanogaster and D. simulans. As in D. melanogaster, D. simulans ppk23-positive sensory neurons activate $\mathrm{VAB} 3$ ascending interneurons, which in turn produce activities in mAL inhibitory interneurons (Seeholzer et al., 2018). Notably, P1 neurons exhibit no apparent activation when vAB3 is depolarized in D. simulans. Upon mAL severing, however, vAB3 activation induces noticeable $\mathrm{Ca}^{2+}$ rises in $\mathrm{P} 1$ neurons (Seeholzer et al., 2018). These observations suggest that both direct excitatory and indirect inhibitory connections between vAB3 and P1 also exist in D. simulans, but in the latter species inhibitory inputs overwhelm excitatory inputs, and, as a consequence, 7,11-HD is unable to activate P1 and thus unable to trigger male courtship behavior in D. simulans (Seeholzer et al., 2018; Figure 2D). This species difference in the integrative functions of the CNS circuit represents a plausible mechanism for the premating isolation between D. melanogaster and D. simulans, which involves contrasting preferences for 7,11-HD: attraction in D. melanogaster males and avoidance in D. simulans males. An intriguing evolutionary scenario is that selective pressure acted on synapses associated with male-specific P1 neurons to shift the balance in favor of excitatory inputs from vAB3 against inhibitory inputs from $\mathrm{mAL}$ in an ancestral species of $D$. melanogaster, when females of this species acquired some dienes as new pheromone components, including 7,11-HD on their cuticles. The postulated shift in the balance between excitatory and inhibitory synaptic efficacies needs to be experimentally demonstrated. Also, if a species difference in the synaptic efficacy exists, as expected, it remains to be determined what genetic change is responsible.

\section{CROSSTALK BETWEEN CONTACT-CHEMOSENSORY AND OLFACTORY PATHWAYS}

In this article, we focused on the contact-chemosensory signaling that plays a key role in mate choice across Drosophila species. However, other sensory modalities also have substantial impacts on partner preference in these flies (Krstic et al., 2009) and the relative contributions of different modalities to mating vary from species to species (Spieth, 1952). Studies in D. melanogaster revealed that males rely primarily on visual (Pan et al., 2012; Kohatsu and Yamamoto, 2015) and auditory (von Schilcher, 1976; Ishikawa et al., 2019) cues in tracking a courtship target, while chemosensory cues play major roles in triggering and maintaining courtship actions. In contrast to chemosensory inputs that impinge onto the courtship decision-making P1 neurons (Kohatsu et al., 2011; Clowney et al., 2015; Kallman et al., 2015), auditory and visual inputs seem to be processed by interneurons distinct from P1 neurons, respectively (Ribeiro et al., 2018; Deutsch et al., 2019). It remains to be clarified how the visual and auditory information is integrated with the P1-dependent command in driving courtship behavior.

In many other insects, volatile compounds are commonly used as pheromones, which are processed by olfactory channels in recipient animals and elicit long distance attraction or avoidance (Fleischer and Krieger, 2018). The best-characterized volatile pheromone in Drosophila is cVA, which acts through both olfactory and contact-chemosensory pathways (Thistle et al., 2012; Ejima, 2015), and thus these two modalities in fact interact to affect fly mating behavior. Crosstalk between the contactchemosensory and olfactory systems in controlling mating and other behaviors is probably prevalent (Wang et al., 2011; Laturney and Billeter, 2016), partly reflecting the fact that the same pheromone compound can exist in either the solid/liquid or vapor state at temperatures a fly engages in reproduction. Of note, 7,11-HD is a precursor of Z-4-undecanal, which is known to function as a long range, species-specific, aggregation pheromone detected by odorant receptor Or69a (Lebreton et al., 2017). Alternatively, it might be that Grs can detect volatile compounds and Ors can detect non-volatile compounds.

Crosstalk between contact chemosensory and olfactory pathways also underlies courtship enhancement by food odor. Phenylacetic acid and phenylacetaldehyde are aromatic odors associated with fruit and other plant tissues that feed Drosophila flies and provide oviposition sites. These compounds are received by IR84a- and fru-expressing olfactory receptor neurons (ORNs) in the antenna. The projection neurons postsynaptic to IR84a ORNs extend their axons into the pheromone-specialist fiber tract even though they convey food odor information (Bates et al., 2020). As a consequence, IR84a-mediated food odor information is sent to a pheromone processing region of the lateral horn, where it is probably integrated together with pheromone information to control mating behavior (Grosjean et al., 2011). Conversely, male-specific cuticular hydrocarbons or cVA deposited onto food promotes landing responses in flying female and male flies, although the neural basis for this effect is not known (Cazalé-Debat et al., 2019; see also Lin et al., 2015; Dumenil et al., 2016). Therefore, crosstalk between contactchemosensory and olfactory information takes place in both the peripheral and central neural circuitries, and the modes of crosstalk appear to be built in a hardwired connectivity blueprint. Which neurons in the mating circuit receive and process inputs from food-odor interneurons remain unknown. In view of the highly variable feeding habits across species, the circuit bases involved in the integration of food odor and mating signals would also be diversified across species.

A recent comparative study on the olfactory basis for hostplant preference in the Drosophila melanogaster subgroup unraveled multilayered modifications at different nodes of olfactory information processing (Auer et al., 2020). Drosophila sechellia is a monophagous species specifically associated with noni fruit (Morinda citrifolia), whereas the sibling species D. simulans is 
polyphagous, as are several other members of the group. Long distance attraction to noni fruit in D. sechellia depends on at least three modifications of the common design for the olfactory circuitry: specialization in the response spectrum of the olfactory receptor Or22a, an increase in the number of Or22a-harboring sensilla, and acquisition of novel terminal arbors in the lateral horn by the DM2 projection neurons that are postsynaptic to Or22a ORNs (Auer et al., 2020). Yet another study suggested that the odorant binding protein genes Obp57d and Obp57e were specialized in $D$. sechellia to make this species prefer noni fruit odor, whereas these genes are required for avoiding noni fruit in the sibling species D. simulans (Matsuo et al., 2007). This study used species hybrids in conducting unbiased screens for genetic loci that are decisive in contrasting noni fruit preferences between $D$. sechellia and $D$. simulans. A similar and even more thorough approach with species hybrids would be fruitful in identifying a collection of genes that are required for diversified mate preferences.

\section{PERSPECTIVES}

The neural mechanism for mating behavior could have accumulated a variety of changes at multiple circuit nodes within the homologous neural pathways across different phylogenetic lineages. Among the members of the D. melanogaster species subgroup, species hybrids are relatively easy to obtain, and would offer an ideal platform for studying genome-wide identifications for loci responsible for species differences in mate preference (Castillo and Barbash, 2017). Indeed, genotypephenotype correlative analyses with whole genome sequencing and behavioral phenotype classification for every hybrid fly is now feasible. Subsequent CRISPR/Cas9-targeted mutagenesis in

\section{REFERENCES}

Ahmed, O. M., Avila-Herrera, A., Tun, K. M., Serpa, P. H., Peng, J., Parthasarathy, S., et al. (2019). Evolution of mechanisms that control mating in Drosophila males. Cell Rep. 27, 2527-2536.e4. doi: 10.1016/j.celrep.2019.04.104

Alves, H., Rouault, J. D., Kondoh, Y., Nakano, Y., Yamamoto, D., Kim, Y. K., et al. (2010). Evolution of cuticular hydrocarbons of Hawaiian Drosophilidae. Behav. Genet. 40, 694-705. doi: 10.1007/s10519-010-9364-y

Antony, C., Davis, T. L., Carlson, D. A., Pechine, J. M., and Jallon, J.-M. (1985). Compared behavioral responses of male Drosophila melanogaster (Canton S) to natural and synthetic aphrodisiacs. J. Chem. Ecol. 11, 1617-1629. doi: 10.1007/ BF01012116

Auer, T. O., Khallaf, M. A., Silbering, A. F., Zappia, G., Ellis, K., ÁlvarezOcaña, R., et al. (2020). Olfactory receptor and circuit evolution promote host specialization. Nature 579, 402-408. doi: 10.1038/s41586-020-2073-7

Bartelt, R. J., Jackson, L. L., and Schaner, A. M. (1985). Ester components of aggregation pheromone of Drosophila virilis (Diptera: Drosophilidae). J. Chem. Ecol. 11, 1197-1208. doi: 10.1007/BF01024108

Bates, A., Schlegel, P., Roberts, R. J. V., Drummond, N., Tamimi, I. F. M., Turnbull, R., et al. (2020). Complete connectomic reconstruction of olfactory projection neurons in the fly brain. Curr. Biol. 30, 3183-3199. doi: 10.1016/j.cub.2020. 06.042

Billeter, J.-C., Attalah, J., Krupp, J., Millar, J. G., and Levine, J. D. (2009). Specialized cells tag sexual and species identity in Drosophila melanogaster. Nature 461, 987-991. doi: 10.1038/nature08495

Bontonou, G., and Wicker-Thomas, C. (2014). Sexual communication in the Drosophila genus. Insects 5, 439-458. doi: 10.3390/insects5020439 conjunction with piggyBac-based transgenic rescue will be used to assure the causality between the gene and behavior (Tanaka et al., 2016, 2017). The entire brain connectome is near completion in D. melanogaster, providing a solid reference map of brain circuitries for the study of neuroanatomy in other members of the D. melanogaster species subgroup. We may soon witness the beginning of a new era in the history of evolutionary studies of the neural basis of reproductive isolation and behavioral divergence.

\section{AUTHOR CONTRIBUTIONS}

DY: conceptualization, review, and editing. KS and DY: funding acquisition and writing the original draft. Both authors contributed to the article and approved the submitted version.

\section{FUNDING}

This work was supported, in part, by Grants-in-Aid for Scientific Research from Ministry of Education, Culture, Sports, Science and Technology (MEXT) to DY (Grant Nos. 19H04923 and 16H06371) and KS (Grant Nos. 19H04766 and 17K07040), a Life Science Grant from the Takeda Science Foundation to DY and KS, and a Hyogo Science and Technology Association Grant to KS.

\section{ACKNOWLEDGMENTS}

We thank current and past members of the Yamamoto laboratory for contributions to the original researches and Y. Takamura for secretarial assistance.

Bousquet, F., Nojima, T., Houot, B., Chauvel, I., Chaudy, I., Dupas, S., et al. (2012). Expression of a desaturase gene, desat1, in neural and nonneural tissues separately affects perception and emission of sex pheromones in Drosophila. Proc. Natl. Acad. Sci. U.S.A. 109, 249-254. doi: 10.1073/pnas.1109166108

Bray, S., and Amrein, H. (2003). A putative Drosophila pheromone receptor expressed in male-specific taste neurons is required for efficient courtship. Neuron 39, 1019-1029. doi: 10.1016/s0896-6273(03)00542-7

Butterwick, J. A., Mármol, J. D., Kim, K. H., Kahlson, M. A., Rogow, J. A., Walz, T., et al. (2018). Cryo-EM structure of the insect olfactory receptor Orco. Nature 560, 447-452. doi: 10.1038/s41586-018-0420-8

Butterworth, F. M. (1969). Lipids of Drosophila: a newly detected lipid in the male. Science 163, 1356-1357. doi: 10.1126/science.163.3873.1356

Cande, J., Namiki, S., Qiu, J., Korff, W., Card, G. M., Shaevits, J. W., et al. (2018). Optogenetic dissection of descending behavioral control in Drosophila. eLife 7:e34275. doi: 10.7554/eLife.34275

Castillo, D. M., and Barbash, D. A. (2017). Moving speciation genetics forward: modern techniques build on foundational studies in Drosophila. Genetics 207, 825-842. doi: 10.1534/genetics.116.187120

Cazalé-Debat, L., Houot, B., Farine, J.-P., Everaerts, C., and Ferveur, J.-F. (2019). Flying Drosophila show sex-specific attraction to fly-labelled food. Sci. Rep. 9:14947. doi: 10.1038/s41598-019-51351-1

Chen, D., Sitaraman, D., Chen, N., Jin, X., Han, C., Chen, J., et al. (2017). Genetic and neuronal mechanisms governing the sex-specific interaction between sleep and sexual behaviors in Drosophila. Nat. Commun. 8:154. doi: 10.1038/s41467017-00087-5

Chertemps, T., Duportets, L., Labeur, C., Ueda, R., Takahashi, K., Saigo, K., et al. (2007). A female-biased expressed elongase involved in long-chain hydrocarbon 
biosynthesis and courtship behavior in Drosophila melanogaster. Proc. Natl. Acad. Sci. U.S.A. 104, 4273-4278. doi: 10.1073/pnas.0608142104

Chertemps, T., Duportets, L., Labeur, C., Ueyama, M., and Wicker-Thomas, C. (2006). A female-specific desaturase gene responsible for diene hydrocarbon biosynthesis and courtship behaviour in Drosophila melanogaster. Insect Mol. Biol. 15, 465-473. doi: 10.1111/j.1365-2583.2006.00658.x

Chin, J. S. R., Ellis, S. R., Pham, H. T., Blanksby, S. J., Mori, K., Koh, Q. L., et al. (2014). Sex-specific triacylglycerides are widely conserved in Drosophila and mediate mating behavior. eLife 3:e01751. doi: 10.7554/eLife.0 1751

Clemens, J., Coen, P., Roemschied, F. A., Pereira, T. D., Mazumder, D., Aldarondo, D. E., et al. (2018). Discovery of a new song mode in Drosophila reveals hidden structure in the sensory and neural drivers of behavior. Curr. Biol. 28, 2400-2412.e6. doi: 10.1016/j.cub.2018.06.011

Clowney, E. J., Iguchi, S., Bussell, J. J., Scheer, E., and Ruta, V. (2015). Multimodal chemosensory circuits controlling male courtship in Drosophila. Neuron 87, 1036-1049. doi: 10.1016/j.neuron.2015.07.025

Clyne, J. D., and Miesenböck, G. (2008). Sex-specific control and tuning of the pattern generator for courtship song in Drosophila. Cell 133, 354-363. doi: 10.1016/j.cell.2008.01.050

Combs, P. A., Krupp, J. J., Khosla, N. M., Bua, D., Petrov, D. A., Levine, J. D., et al. (2018). Tissue-specific cis-regulatory divergence implicates eloF in inhibiting interspecies mating in Drosophila. Curr. Biol. 28, 3969-3975.e3. doi: 10.1016/j. cub.2018.10.036

Costa, M., Manton, J., Ostrovsky, A., Prohaska, S., and Jefferis, G. S. X. E. (2016). NBLAST: rapid, sensitive comparison of neuronal structure and construction of neuron family databases. Neuron 91, 293-311. doi: 10.1016/j.neuron.2016. 06.012

Coyne, J. A., and Orr, H. A. (2004). Speciation. (Oxford: Oxford University Press), 545.

Crickmore, M. A., and Vosshall, L. B. (2013). Opposing dopaminergic and GABAergic neurons control the duration and persistence of copulation in Drosophila. Cell 155, 881-893. doi: 10.1016/j.cell.2013.09.055

Dallerac, R., Labeur, C., Jallon, J.-M., Knipple, D. C., Roelofs, W. L., and WickerThomas, C. (2000). A $\Delta 9$ desaturase gene with a different substrate specificity is responsible for the cuticular diene hydrocarbon polymorphism in Drosophila melanogaster. Proc. Natl. Acad. Sci. U.S.A. 97, 9449-9454. doi: 10.1073/pnas. 150243997

Datta, S. R., Vasconcelos, M. L., Ruta, V., Luo, S., Wong, A., Demir, E., et al. (2008). The Drosophila pheromone cVA activates a sexually dimorphic neural circuit. Nature 452, 473-477. doi: 10.1038/nature06808

Deutsch, D., Clemens, J., Thiberge, S. Y., Guan, G., and Murthy, M. (2019). Shared song detector neurons in Drosophila male and female brains drive sex-specific behaviors. Curr. Biol. 29, 3200-3215.e5. doi: 10.1016/j.cub.2019.08.008

Dumenil, C., Woud, D., Pinto, F., Alkema, J. T., Jansen, I., Van der Geest, A. M., et al. (2016). Pheromonal cues deposited by mated females convey social information about egg-laying sites in Drosophila melanogaster. J. Chem. Ecol. 42, 259-269. doi: 10.1007/s10886-016-0681-3

Dweck, H. K. M., and Carlson, J. R. (2020). Molecular logic and evolution of bitter taste in Drosophila. Curr. Biol. 30, 17-30.e3. doi: 10.1016/j.cub.2019.11.005

Dweck, H. K. M., Ebrahim, S. A., Thoma, M., Mohamed, A. A., Keesey, I. W., Trona, F., et al. (2015). Pheromones mediating copulation and attraction in Drosophila. Proc. Natl. Acad. Sci. U.S.A. 112, E2829-E2835. doi: 10.1073/pnas. 1504527112

Ejima, A. (2015). Pleiotropic actions of the male pheromone cis-vaccenyl acetate in Drosophila melanogaster. J. Comp. Physiol. A. 201, 927-932. doi: 10.1007/ s00359-015-1020-9

Ejima, A., Smith, B. P. C., Lucas, C., Naters, W. G., Miller, C. J., Carlson, J. R., et al. (2007). Generalization of courtship learning in Drosophila is mediated by cis-vaccenyl acetate. Curr. Biol. 17, 599-605. doi: 10.1016/j.cub.2007.01.053

Fan, P., Manoli, D. S., Ahmed, S. M., Chen, Y., Agarwal, N., Kwong, S., et al. (2013). Genetic and neural mechanisms that inhibit Drosophila from mating with other species. Cell 154, 89-102. doi: 10.1016/j.cell.2013.06.008

Ferveur, J.-F. (1997). The pheromonal role of cuticular hydrocarbons in Drosophila melanogaster. Bioessays 19, 353-358. doi: 10.1002/bies.950190413

Fleischer, J., and Krieger, J. (2018). Insect pheromone receptors - Key elements in sensing intraspecific chemical signals. Front. Cell. Neurosci. 12:425. doi: $10.3389 /$ fncel.2018.00425
Grillet, M., Everaerts, C., Houot, B., Ritchie, M. G., Cobb, M., and Ferveur, J.F. (2012). Incipient speciation in Drosophila melanogaster involves chemical signals. Sci. Rep. 2:224. doi: 10.1038/srep00224

Grosjean, Y., Rytz, R., Farine, J.-P., Abuin, L., Cortot, J., Jefferis, G. S. X. E., et al. (2011). An olfactory receptor for food-derived odours promotes male courtship in Drosophila. Nature 478, 236-240. doi: 10.1038/nature10428

Grover, D., Katsuki, T., and Greenspan, R. (2016). Flyception: imaging brain activity in freely walking fruit flies. Nat. Methods 13, 569-572. doi: 10.1038/ nmeth.3866

Grover, D., Katsuki, T., Li, J., Dawkins, T. J., and Greenspan, R. (2020). Imaging brain activity during complex social behaviors in Drosophila with Flyception2. Nat. Commun. 11:623. doi: 10.1038/s41467-020-14487-7

Guiraudie-Capraz, G., Pho, D. B., and Jallon, J.-M. (2007). Role of the ejaculatory bulb in biosynthesis of the male pheromone cis-vaccenyl acetate in Drosophila melanogaster. Integr. Zool. 2, 89-99. doi: 10.1111/j.1749-4877.2007.00047.x

Ha, T. S., and Smith, D. P. (2006). A pheromone receptor mediates 11-cis-vaccenyl acetate-induced responses in Drosophila. J. Neurosci. 26, 8727-8733. doi: 10. 1523/JNEUROSCI.0876-06.2006

Hales, K. G., Korey, C. A., Larracuente, A. M., and Roberts, D. M. (2015). Genetics on the fly: a primer on the Drosophila model system. Genetics 201, 815-842. doi: 10.1534/genetics.115.183392

He, Z., Luo, Y., Shang, X., Sun, J. S., and Carlson, J. R. (2019). Chemosensory sensilla of the Drosophila wing express a candidate ionotropic pheromone receptor. PLoS Biol. 17:e2006619. doi: 10.1371/journal.pbio.2006619

Hoopfer, E., Jung, Y., Inagaki, H. K., Rubin, G. M., and Anderson, D. J. (2015). P1 interneurons promote a persistent internal state that enhances inter-male aggression in Drosophila. eLife 4:e11346. doi: 10.7554/eLife.11346

Inagaki, H. K., Jung, Y., Hoopfer, E. D., Wong, A. M., Mishra, N., Lin, J. Y., et al. (2014). Optogenetic control of Drosophila using a red-shifted channelrhodopsin reveals experience-dependent influences on courtship. Nat. Methods 11, 325332. doi: $10.1038 /$ nmeth. 2765

Ishii, K., Wohl, M., DeSouza, A., and Asahina, K. (2020). Sex-determining genes distinctly regulate courtship capability and target preference via sexually dimorphic neurons. eLife 9:e52701. doi: 10.7554/eLife.52701

Ishikawa, Y., Okamoto, N., Yoneyama, Y., Maeda, N., and Kamikouchi, A. (2019). A single male auditory response test to quantify auditory behavioral responses in Drosophila melanogaster. J. Neurogenet. 33, 64-74. doi: 10.1080/01677063. 2019.1611805

Jallon, J.-M. (1984). A few chemical words exchanged by Drosophila during courtship and mating. Behav. Genet. 14, 441-478. doi: 10.1007/BF01065444

Jallon, J.-M., and David, J. R. (1987). Variations in cuticular hydrocarbons among the eight species of the Drosophila melanogaster subgroup. Evolution 41, 294302. doi: 10.1111/j.1558-5646.1987.tb05798.x

Kallman, B., Kim, H., and Scott, K. (2015). Excitation and inhibition onto central courtship neurons biases Drosophila mate choice. eLife 4:e11188. doi: 10.7554/ eLife. 11188

Keleman, K., Vrontou, E., Krüttner, S., Yu, J. Y., K-Kozaic, A., and Dickson, B. J. (2012). Dopamine neurons modulate pheromone responses in Drosophila courtship learning. Nature 489, 145-149. doi: 10.1038/nature11345

Kimura, K.-I., Hachiya, T., Koganezawa, M., Tazawa, T., and Yamamoto, D. (2008). Fruitless and doublesex coordinate to generate male-specific neurons that can initiate courtship. Neuron 59, 759-769. doi: 10.1016/j.neuron.2008.06.007

Kimura, K.-I., Ote, M., Tazawa, T., and Yamamoto, D. (2005). Fruitless specifies sexually dimorphic neural circuitry in the Drosophila brain. Nature 438, 229233. doi: 10.1038/nature04229

Kimura, K.-I., Sato, C., Yamamoto, K., and Yamamoto, D. (2015). From the back or front: the courtship position is a matter of smell and sight in Drosophila melanogaster males. J. Neurogenet. 29, 18-22. doi: 10.3109/01677063.2014. 968278

Kimura, K.-I., Urushizaki, A., Sato, C., and Yamamoto, D. (2019). A novel sex difference in Drosophila contact chemosensory neurons unveiled using single cell labeling. J. Neurogenet. 33, 116-124. doi: 10.1080/01677063.2018.1531858

Koganezawa, M., Haba, D., Matsuo, T., and Yamamoto, D. (2010). The shaping of male courtship posture by lateralized gustatory inputs to male-specific interneurons. Curr. Biol. 20, 1-8. doi: 10.1016/j.cub.2009.11.038

Koganezawa, M., Kimura, K.-I., and Yamamoto, D. (2016). The neural circuitry that functions as a switch for courtship versus aggression in Drosophila males. Curr. Biol. 26, 1395-1403. doi: 10.1016/j.cub.2016.04.017 
Koh, R. Q., He, Z., Gorur-Shandilya, S., Menuz, K., Larter, N., Stewart, S., et al. (2014). The Drosophila IR20a clade of ionotropic receptors are candidate taste and pheromone receptors. Neuron 83, 850-865. doi: 10.1016/j.neuron.2014. 07.012

Kohatsu, S., Koganezawa, M., and Yamamoto, D. (2011). Female contact activates male-specific interneurons that trigger stereotypic courtship behavior in a Drosophila male. Neuron 69, 498-508. doi: 10.1016/j.neuron.2010.12.017

Kohatsu, S., and Yamamoto, D. (2015). Visually induced initiation of Drosophila innate courtship-like following pursuit is mediated by central excitatory state. Nat. Commun. 6:6457. doi: 10.1038/ncomms7457

Kohl, J., Huoviala, P., and Jefferis, G. S. X. E. (2015). Pheromone processing in Drosophila. Curr. Opin. Neurobiol. 34, 149-157. doi: 10.1016/j.conb.2015. 06.009

Kohl, J., Ostrovsky, A. D., Frechter, S., and Jefferis, G. S. X. E. (2013). A bidirectional circuit switch reroutes pheromone signals in male and female brains. Cell 155, 1610-1623. doi: 10.1016/j.cell.2013.11.025

Krstic, D., Boll, W., and Noll, M. (2009). Sensory integration regulating male courtship behavior in Drosophila. PLoS One 4:e4457. doi: 10.1371/journal.pone. 0004457

Kurtovic, A., Widmer, A., and Dickson, B. J. (2007). A single class of olfactory neurons mediates behavioural responses to a Drosophila sex pheromone. Nature 446, 542-546. doi: 10.1038/nature05672

Lacaille, F., Hiroi, M., Twele, R., Inoshita, T., Umemoto, D., Manière, G., et al. (2007). An inhibitory sex pheromone tastes bitter for Drosophila males. PLoS One 2:e661. doi: 10.1371/journal.pone.000

Laturney, M., and Billeter, J.-C. (2016). Drosophila melanogaster females restore their attractiveness after mating by removing male. Nat. Commun. 7:12322. doi: $10.1038 /$ ncomms 12322

Lebreton, S., Borrero-Echeverry, F., Gonzalez, F., Solum, M., Wallin, E. A., Hedenström, E., et al. (2017). A Drosophila female pheromone elicits species-specific long-range attraction via an olfactory channel with dual specificity for sex and food. BMC Biol. 15:88. doi: 10.1186/s12915-0170427-x

Lebreton, S., Grabe, V., Omondi, A. B., Ignell, R., Becher, P. G., Hansson, B. S., et al. (2014). Love makes smell blind: mating suppresses pheromone attraction in Drosophila females via Or65a olfactory neurons. Science 4:7119. doi: 10.1038/ srep07119

Lin, C. C., Prokop-Prigge, K. A., Preti, G., and Potter, C. J. (2015). Food odors trigger Drosophila males to deposit a pheromone that guides aggregation and female oviposition decisions. eLife 4:e08688. doi: 10.7554/eLife.08688

Lin, H. H., Cao, D. S., Sethi, S., Zeng, Z., Chin, J. S. R., Chakraborty, T. S., et al. (2016). Hormonal modulation of pheromone detection enhances male courtship success. Neuron 90, 1272-1285. doi: 10.1016/j.neuron.2016.05.004

Ling, F., Dahanukar, A., Weiss, L. A., Kwon, J. Y., and Carlson, J. R. (2014). The molecular and cellular basis of taste coding in the legs of Drosophila. J. Neurosci. 34, 7148-7164. doi: 10.1523/JNEUROSCI.0649-14.2014

Liu, T., Starostina, E., Vijayan, V., and Pikielny, C. W. (2012). Two Drosophila $\mathrm{DEG} / \mathrm{ENaC}$ channel subunits have distinct functions in gustatory neurons that activate male courtship. J. Neurosci. 32, 11879-11889. doi: 10.1523/ JNEUROSCI.1376-12.2012

Liu, T., Wang, Y., Tian, Y., Zhang, J., Zhao, J., and Guo, A. (2020). The receptor channel formed by $p p k 25, p p k 29$ and $p p k 23$ can sense the Drosophila female pheromone 7,11-heptacosadiene. Genes Brain Behav. 19:e12529. doi: 10.1111/ gbb. 12529

Liu, W., Liang, X., Gong, J., Yang, Z., Zhang, Y. H., Zhang, J. X., et al. (2011). Social regulation of aggression by pheromonal activation of Or65a olfactory neurons in Drosophila. Nat. Neurosci. 14, 896-902. doi: 10.1038/nn.2836

Lu, B., LaMora, A., Sun, Y., Welsh, M. J., and Ben-Shahar, Y. (2012). ppk23dependent chemosensory functions contribute to courtship behavior in Drosophila melanogaster. PLoS Genet. 8:e1002587. doi: 10.1371/journal.pgen. 1002587

Matsuo, T., Sugaya, S., Yasukawa, J., Aigaki, T., and Fuyama, Y. (2007). Odorantbinding proteins OBP57d and OBP57e affect taste perception and host-plant preference in Drosophila sechellia. PLoS Biol. 5:e118. doi: 10.1371/journal.pbio. 0050118

McKellar, C., Lillvis, J. L., Bath, D. E., Fitzgerald, J. E., Cannon, J. G., Simpson, J. H., et al. (2019). Threshold-based ordering of sequential actions during Drosophila courtship. Curr. Biol. 29, 426-434.e6. doi: 10.1016/j.cub.2018.12.019
Mellert, D. M., Knapp, J. M., Manoli, D. S., Meissner, G. W., and Baker, B. S. (2010). Midline crossing by gustatory receptor neuron axons is regulated by fruitless, doublesex and the Roundabout receptors. Development 137, 323-332. doi: 10.1242/dev.045047

Namiki, S., Dickinson, M. H., Wong, A. M., Karff, W., and Card, G. M. (2018). The functional organization of descending sensory-motor pathways in Drosophila. eLife 7:e34272. doi: 10.7554/eLife.34272

Ng, R., Salem, S. S., Wu, S. T., Wu, M., Lin, H. H., Shepherd, A. K., et al. (2019). Amplification of Drosophila olfactory responses by a DEG/ENaC channel. Neuron 104, 947-959.e5. doi: 10.1016/j.neuron.2019. 08.041

Ng, W. C., Chin, J. S., Tan, K. J., and Yew, J. Y. (2015). The fatty acid elongase Bond is essential for Drosophila sex pheromone synthesis and male fertility. Nat. Commun. 6:8263.

Pan, Y., Meissner, G. W., and Baker, B. S. (2012). Joint control of Drosophila male courtship behavior by motion cues and activation of male-specific P1 neurons. Proc. Natl. Acad. Sci. U.S.A. 109, 10065-10070. doi: 10.1073/pnas.1207107109

Qiu, Y., Tittiger, C., Wicker-Thomas, C., Le Goff, G., Young, S., Wajnberg, E., et al. (2012). An insect-specific P450 oxidative decarbonylase for cuticular hydrocarbon biosynthesis. Proc. Natl. Acad. Sci. U.S.A. 109, 14858-14863. doi: 10.1073/pnas.1208650109

Ren, Q., Awasaki, T., Huang, Y. F., Liu, Z., and Lee, T. (2016). Cell class-lineage analysis reveals sexually dimorphic lineage compositions in the Drosophila brain. Curr. Biol. 26, 2583-2593. doi: 10.1016/j.cub.2016.07.086

Ribeiro, I. M. A., Drews, M., Bahl, A., Machacek, C., Borst, A., and Dickson, B. J. (2018). Visual projection neurons mediating directed courtship in Drosophila. Cell 174, 607-621.e18. doi: 10.1016/j.cell.2018.06.020

Ruta, V., Datta, S. R., Vasconcelos, L. V., Freeland, J., Looger, L. L., and Axel, R. (2010). A dimorphic pheromone circuit in Drosophila from sensory input to descending output. Nature 468, 686-690. doi: 10.1038/nature09554

Sato, K., Pellegrino, M., Nakagawa, T., Nakagawa, T., Vosshall, L. B., and Touhara, K. (2008). Insect olfactory receptors are heteromeric ligand-gated ion channels. Nature 452, 1002-1006. doi: 10.1038/nature06850

Sato, K., Tanaka, K., and Touhara, K. (2011). Sugar-regulated cation channel formed by an insect gustatory receptor. Proc. Natl. Acad. Sci. U.S.A. 108, 11680-11685. doi: 10.1073/pnas.1019622108

Seeholzer, L., Seppi, M., Stern, D., and Ruta, V. (2018). Evolution of a central neural circuit underlies Drosophila mate preferences. Nature 559, 564-569. doi: 10.1038/s41586-018-0322-9

Shirangi, T. T., Dufour, H. D., Williams, T. M., and Carroll, S. B. (2009). Rapid evolution of sex pheromone-producing enzyme expression in Drosophila. PLoS Biol. 7:e1000168. doi: 10.1371/journal.pbio.10 00168

Shumer, M., Powell, D. L., Delclós, P. J., Squire, M., Cui, R., Andolfatto, P., et al. (2017). Assortative mating and persistent reproductive isolation in hybrids. Proc. Natl. Acad. Sci. U.S.A. 114, 10936-10941. doi: 10.1073/pnas.1711238114

Skiba, P. J., and Jackson, L. L. (1993). (Z)-10-heptadecen-2-one and 2tridecanone biosynthesis from [1-14C]acetate by Drosophila buzzatii. Insect Biochem. Mol. Biol. 23, 375-380. doi: 10.1016/0965-1748(93)9 0021-J

Spieth, H. T. (1952). Mating behavior within the genus Drosophila (Diptera). Bull. Am. Mus. Nat. 99, 399-474.

Starostina, E., Liu, T., Vijayan, V., Zheng, Z., Siwicki, K. K., and Pikielny, C. W. (2012). A Drosophila DEG/ENaC subunit functions specifically in gustatory neurons required for male courtship behavior. J. Neurosci. 32, 4665-4674. doi: 10.1523/JNEUROSCI.6178-11.2012

Sweigart, A. L. (2010). The genetics of postmating, prezygotic reproductive isolation between Drosophila virilis and D. americana. Genetics 184, 401-410. doi: 10.1534/genetics.109.111245

Symonds, M. R. E., and Wertheim, B. (2005). The mode of evolution of aggregation pheromones in Drosophila species. J. Evol. Biol. 18, 1253-1263. doi: 10.1111/j. 1420-9101.2005.00971.x

Takahashi, A., Tsaur, S. C., Coyne, J. A., and Wu, C. I. (2001). The nucleotide changes governing cuticular hydrocarbon variation and their evolution in Drosophila melanogaster. Proc. Natl. Acad. Sci. U.S.A. 98, 3920-3925. doi: 10. 1073/pnas.061465098

Tanaka, R., Higuchi, T., Kohatsu, S., Sato, K., and Yamamoto, D. (2017). Optogenetic activation of the fruitless-labeled circuitry in Drosophila subobscura 
males induces mating motor acts. J. Neurosci. 37, 11662-11674. doi: 10.1523/ JNEUROSCI.1943-17.2017

Tanaka, R., Murakami, H., Ote, M., and Yamamoto, D. (2016). Clustered regulatory interspaced short palindromic repeats (CRISPR)-mediated mutagenesis and phenotype rescue by piggyBac transgenesis in a nonmodel Drosophila species. Insect Mol. Biol. 25, 355-361. doi: 10.1111/imb.12232

Thistle, R., Camaeron, P., Ghorayshi, A., Dennison, L., and Scott, K. (2012). Contact chemoreceptors mediate male-male repulsion and male-female attraction during Drosophila courtship. Cell 149, 1140-1151. doi: 10.1016/j.cell. 2012.03.045

Thompkins, L., McRobert, S., and Kaneshiro, K. Y. (1993). Chemical communication in Hawaiian Drosophila. Evolution 47, 1407-1419. doi: 10.1111/j.1558-5646.1993.tb02163.x

Toda, H., Zhao, X., and Dickson, B. J. (2012). The Drosophila female aphrodisiac pheromone activates $p p k 23(+)$ sensory neurons to elicit male courtship behavior. Cell Rep. 1, 599-607. doi: 10.1016/j.celrep.2012.05.007

Vijayan, V., Thistle, R., Liu, T., Starostina, E., and Pikielny, C. W. (2014). Drosophila pheromone-sensing neurons expressing the Ppk25 ion channel subunit stimulate male courtship and female receptivity. PLoS Genet. 10:e1004238. doi: 10.1371/journal.pgen.1004238

von Philipsborn, A. C., Liu, T., Yu, J. Y., Masser, C., Bidaye, S. S., and Dickson, B. J. (2011). Neuronal control of Drosophila courtship song. Neuron 69, 509-522. doi: 10.1016/j.neuron.2011.01.011

von Schilcher, F. (1976). The role of auditory stimuli in the courtship of Drosophila melanogaster. Anim. Behav. 24, 18-26. doi: 10.1016/s0003-3472(76)80095-4

Wang, L., and Anderson, D. J. (2010). Identification of an aggression-promoting pheromone and its receptor neurons in Drosophila. Nature 463, 227-231. doi: 10.1038/nature08678

Wang, L., Han, X., Mehren, J., Hiroi, M., Billeter, J.-C., Miyamoto, T., et al. (2011). Hierarchical chemosensory regulation of male-male social interactions in Drosophila. Nat. Neurosci. 14, 757-762. doi: 10.1038/nn.2800

Watanabe, K., Toba, G., Koganezawa, M., and Yamamoto, D. (2011). Gr39a, a highly diversified gustatory receptor in Drosophila, has a role in sexual behavior. Behav. Genet. 41, 746-753. doi: 10.1007/s10519-011-9461-6

Wertheim, B., Dicke, M., and Vet, L. E. M. (2002). Behavioural plasticity in support of a benefit for aggregation pheromone use in Drosophila melanogaster. Entomol. Exp. Appl. 103, 61-71. doi: 10.1046/j.1570-7458.2002.00954.x

Wicker-Thomas, C., Guenachi, I., and Keita, Y. F. (2009). Contribution of oenocytes and pheromones to courtship behaviour in Drosophila. BMC Biochem. 10:21. doi: 10.1186/1471-2091-10-21
Wohl, M., Ishii, K., and Asahina, K. (2020). Layered roles of Fruitless isoforms in specification and function of male aggression-promoting neurons in Drosophila. eLife 9:e52702. doi: 10.7554/eLife.52702

Wu, C. I., Hollocher, H., Gegun, D. J., Aquadro, C. F., Xu, Y., and Wu, M. L. (1995). Sexual isolation in Drosophila melanogaster: a possible case of incipient speciation. Proc. Natl. Acad. Sci. U.S.A. 92, 2519-2523. doi: 10.1073/pnas.92.7. 2519

Wu, S., Guo, C., Zhao, H., Sun, M., Chen, J., Han, C., et al. (2019). Drosulfakinin signaling in fruitless circuitry antagonizes $\mathrm{P} 1$ neurons to regulate sexual arousal in Drosophila. Nat. Commun. 10:4770. doi: 10.1038/s41467-019-12758-6

Yamamoto, D., and Koganezawa, M. (2013). Genes and circuits of courtship behaviour in Drosophila males. Nat. Rev. Neurosci. 14, 681-692. doi: 10.1038/ nrn3567

Yew, J. Y., and Chung, H. (2017). Drosophila as a holistic model for insect pheromone signaling and processing. Curr. Opin. 24, 15-20. doi: 10.1016/j.cois. 2017.09.003

Yew, J. Y., Dreisewerd, K., Luftmann, H., Müthing, J., Pohlentz, G., and Kravitz, E. A. (2009). A new male sex pheromone and novel cuticular cues for chemical communication in Drosophila. Curr. Biol. 19, 1245-1254. doi: 10.1016/j.cub. 2009.06.037

Yu, J. Y., Kanai, M. I., Demir, E., Jefferis, G. S. X. E., and Dickson, B. J. (2010). Cellular organization of the neural circuit that drives Drosophila courtship behavior. Curr. Biol. 20, 1602-1614. doi: 10.1016/j.cub.2010.08.025

Zhang, S. X., Miner, L. E., Boutros, C. L., Rogulja, D., and Crickmore, M. A. (2018). Motivation, perception, and chance converge to make a binary decision. Neuron 99, 376-388.e6. doi: 10.1016/j.neuron.2018.06.014

Zhang, S. X., Rogulja, D., and Crickmore, M. A. (2016). Dopaminergic circuitry underlying mating drive. Neuron 91, 168-181. doi: 10.1016/j.neuron.2016. 05.020

Conflict of Interest: The authors declare that the research was conducted in the absence of any commercial or financial relationships that could be construed as a potential conflict of interest.

Copyright (c) 2020 Sato and Yamamoto. This is an open-access article distributed under the terms of the Creative Commons Attribution License (CC BY). The use, distribution or reproduction in other forums is permitted, provided the original author(s) and the copyright owner(s) are credited and that the original publication in this journal is cited, in accordance with accepted academic practice. No use, distribution or reproduction is permitted which does not comply with these terms. 